\title{
Long-Lasting Increase of Alcohol Relapse by the Cannabinoid Receptor Agonist WIN 55,212-2 during Alcohol Deprivation
}

\author{
José Antonio López-Moreno, ${ }^{1}$ Gustavo González-Cuevas, ${ }^{1}$ Fernando Rodríguez de Fonseca, ${ }^{2}$ and Miguel Navarro ${ }^{1}$ \\ ${ }^{1}$ Departamento de Psicobiología, Facultad de Psicología, Universidad Complutense de Madrid, E-28223 Madrid, Spain, and ²Unidad de Investigación, \\ Fundación Hospital Carlos Haya, 29010 Málaga, Spain
}

\begin{abstract}
Alcoholism is characterized by successive relapses. Recent data have shown a cross-talk between the cannabinoid system and ethanol. In this study, male Wistar rats with a limited (30 min sessions), intermittent, and extended background of alcohol operant selfadministration were used. The relapse to alcohol after 1 week of alcohol deprivation was evaluated. Two weeks later, the animals were treated with the cannabinoid agonist WIN 55,212-2 $(R-(+)-[2,3-$ dihydro-5-methyl-3-(4-morpholinylmethyl)pyrrolo[1,2,3-de]-1,4benzoxazin-6-yl]-1-naphthalenylmethanone mesylate) $(0,0.4,2.0$, and $10.0 \mathrm{mg} / \mathrm{kg}$, s.c.) during a similar alcohol deprivation period, and alcohol relapse during 2 weeks was assessed. A conditioned place preference (CPP) paradigm was used to study the rewarding properties of the cannabinoid agonist. Locomotor activity was also recorded. All doses of WIN 55,212-2 produced aversion in the CPP paradigm. The doses of 2.0 and $10.0 \mathrm{mg} / \mathrm{kg}$ resulted in an important suppression of spontaneous locomotor activity and a progressive weight loss during the next 2 weeks. The single alcohol deprivation was followed by a transient increase in their responding for alcohol from a range of $20-24$ lever presses at baseline to a range of 38-48 responses in the first and second days (alcohol deprivation effect). However, the administration of WIN 55,212-2 during ethanol deprivation produced similar increased responses for alcohol but in a long-term way (at least over 2 weeks). These findings suggest that noncontingent chronic exposure to cannabinoids during alcohol deprivation can potentiate the relapse into alcohol use, indicating that functional changes in the cannabinoid brain receptor may play a key role in ethanol relapse.
\end{abstract}

Key words: cannabinoid; WIN 55,212-2; ethanol operant self-administration; alcohol deprivation; relapse; craving

\section{Introduction}

The involvement of the endocannabinoid system in the effects of ethanol $(\mathrm{EtOH})$ has been demonstrated recently in behavioral and biochemical experiments and using knock-out mice. In Sardinian alcohol-preferring rats, the administration of two synthetic cannabinoid agonists of the cannabinoid brain $\left(\mathrm{CB}_{1}\right)$ receptor WIN 55,212-2 mesylate $(R-(+)$-[2,3-dihydro-5-methyl-3-(4morpholinylmethyl)pyrrolo[1,2,3-de]-1,4-benzoxazin-6-yl]-1naphthalenylmethanone mesylate) and CP55,940 ((-)-cis-3-[2hydroxy-4-(1,1-dimethylheptyl)phenyl]-trans-4-(3-hydroxypropyl)cyclohexanol), induced a dose-dependent increase in EtOH intake (Colombo et al., 2002). In contrast, the $\mathrm{CB}_{1}$ receptor antagonist has been shown to control EtOH consumption, as observed by prevention of acquisition of drinking behavior

\footnotetext{
Received April 1, 2004; revised July 19, 2004; accepted July 21, 2004.

This work was supported by The European Fifth Framework Programme, TargAlc Grants QLRT-2000-01691 and QLRT-2001-01048 (M.N. and F.R.d.F.), Ministerio de Ciencia y Tecnología Grant BFI-2001-C02-01, and Fondo de Investigación Sanitaria (Red de Trastornos Adictivos G03/05). We thank Luis Franco for his help in the support and maintenance of the conditioned place preference apparatus and chambers of operant self-administration, José Mauricio Flórez de Uría and Santiago Climent for the development of the computer software, Dr. Inmaculada Herranz for statistical assistance, Dr. Esther O'Shea for English assistance, and Dr. Marta Pulido for editing this manuscript and editorial assistance.

Correspondence should be addressed to Miguel Navarro, Departamento de Psicobiología, Facultad de Psicología, Campus Somosaguas, Universidad Complutense de Madrid, E-28223 Madrid, Spain. E-mail: mnavarro@psi.ucm.es. DOI:10.1523/JNEUROSCI.2179-04.2004

Copyright $\odot 2004$ Society for Neuroscience $\quad$ 0270-6474/04/248245-08\$15.00/0
}

(Serra et al., 2001) and the ability for decreasing EtOH operant self-administration (Rodríguez de Fonseca et al., 1999) and reducing relapse to EtOH self-administration, evaluated by the alcohol deprivation effect (Serra et al., 2002).

In biochemical studies, chronic alcohol treatment increased the levels of the endogenous ligands for cannabinoid receptors arachidonoylethanolamide and 2-arachidonoyl-glycerol (Basavarajappa and Hungund, 2002). Additionally, chronic alcohol exposure induced a decrease in the number of $\mathrm{CB}_{1}$ receptors and a desensitization of the cannabinoid-activated signal transduction (Basavarajappa and Hungund, 2002). A similar downregulation of these receptors was observed after chronic treatment with the natural cannabinoid agonist $\Delta^{9}$-tetra-hydrocannabinol or with CP-55,940 (Rodríguez de Fonseca et al., 1994; Rubino et al., 1994; Breivogel et al., 2003). In studies with mice lacking the cannabinoid $\mathrm{CB}_{1}$ receptor $\left(\mathrm{CB}_{1}{ }^{-1-}\right)$, a decrease in both voluntary $\mathrm{EtOH}$ intake and $\mathrm{EtOH}$ operant self-administration was found (Hungund et al., 2003; Naassila et al., 2004).

In animals, the alcohol deprivation effect is characterized by a transient increase in ethanol consumption after a period of forced abstinence (Sinclair and Senter, 1967), providing a suitable model to study the psychopharmacologic characteristics of alcohol relapse. The validity of the alcohol deprivation effect model has been demonstrated using different substances. Acamprosate and naltrexone, alone or in combination, the $\mathrm{GABA}_{\mathrm{B}}$ receptor 
agonist baclofen, the NMDA receptor antagonist memantine, and the cannabinoid antagonist SR141716 (N-piperidino-5-(4chlorophenyl)-1-(2,4-dichlorophenyl)-4-methyl-3-pyrazole carboxamide) are effective in suppressing the alcohol deprivation effect (Hölter et al., 1996; Spanagel et al., 1996; Heyser et al., 1998, 2003; Colombo et al., 2003). It has been suggested that the alcohol deprivation effect is related to alcohol craving, defined as a desire for the previously experienced effect of EtOH (Koob, 2000), and would be a major determinant of alcohol relapse after abstinence periods.

The present experiments were designed to determine the role of the $\mathrm{CB}_{1}$ receptor in the relapse into alcohol consumption. The alcohol deprivation effect model was used to test the hypothesis that chronic exposure to cannabinoids can alter the responses to alcohol, even when the interaction of both drugs at one time is avoided. To assess whether the contribution of the cannabinoid system may be independent of contextual cues, we studied the effect of the cannabinoid agonist WIN 55,212-2 in a situation different from that of the operant self-administration chambers, thus avoiding any conditioning process over the alcohol intake period. Furthermore, we evaluated the rewarding effects of WIN $55,212-2$ in the conditioned place preference (CPP) paradigm as well as the locomotor activity of the animals during alcohol deprivation.

\section{Materials and Methods}

Animals. Adult male Wistar rats (Harlan, Barcelona, Spain) weighing 200-225 gm at the start of the experiment were housed two per cage in a room with controlled photoperiod (the light was turned on at 8:00 P.M.) and controlled temperature-humidity environment $\left(23 \pm 1^{\circ} \mathrm{C}\right)$. Food and water were available ad libitum in the home cage. All experiments were conducted under dim red light between 9:00 A.M. and 7:00 P.M. During the 2 week period before experiments, rats were handled by the experimenters once daily for 5 min during the dark phase to habituate the animals to human manipulation. All procedures described in the present study were in accordance with the National Institutes of Health Guide for the Care and Use of Laboratory Animals.

Drugs. WIN 55,212-2 (Tocris Cookson, Bristol, UK) was dissolved in sterile physiological saline with $0.1 \%$ Tween 80 and administered in a volume of $1 \mathrm{ml} / \mathrm{kg}$. All the doses of WIN 55,212-2 were prepared daily and injected subcutaneously between the shoulder blades. Alcohol solution was prepared daily as a $10 \%$ alcohol w/v solution from $96 \%$ pure ethanol (Panreac Química, Barcelona, Spain).

Experiments. The animals were exposed to intermittent (Monday to Friday) and limited (30 min sessions) access to alcohol per week. Once baseline had been reached after at least a 5 week period of access to alcohol $(10 \% \mathrm{w} / \mathrm{v})$, animals were alcohol deprived for 1 week in their home cage. Two weeks after resuming alcohol access (weeks 1 and 2 after deprivation), the animals were ethanol deprived again and concomitantly received the cannabinoid agonist WIN 55,212-2 mesylate during $5 \mathrm{~d}$ (Monday to Friday). The exposure to WIN 55,212-2 was performed under the CPP paradigm. The locomotor activity was registered during the 30 min sessions. Finally, the animals were reintroduced into the operant ethanol chambers of self-administration for 2 more weeks (11-12 animals per group). The rats were always weighed immediately before the start the session (self-administration or CPP trial).

Training procedure for oral ethanol self-administration. Training was achieved using a modification of the method described by Samson et al. (1999). Briefly, rats were placed on a food restriction schedule for 2-4 d to facilitate training of lever pressing. During the first $3 \mathrm{~d}$ of training, the animals received $20 \%$ sucrose solution in the dipper. Thereafter, the following sequence on a fixed-ratio 1 schedule was used: $20 \%$ sucrose for two sessions, $10 \%$ sucrose and $2 \%$ EtOH for two sessions, $8 \%$ sucrose and $4 \% \mathrm{EtOH}$ for two sessions, $6 \%$ sucrose and $6 \% \mathrm{EtOH}$ for four sessions, $4 \%$ sucrose and $8 \% \mathrm{EtOH}$ for four sessions, $2 \%$ sucrose and $10 \%$ $\mathrm{EtOH}$ for four sessions, and 10\% EtOH for 10-20 sessions. All the sessions were conducted during the dark phase of the light/dark cycle and were $30 \mathrm{~min} / \mathrm{d}$ in duration over $5 \mathrm{~d}$ /week (Monday to Friday). Selfadministration sessions were conducted in modular chambers (Letica, LE 850 model; Panlab, Barcelona, Spain) enclosed in sound-attenuating cubicles. The chambers were equipped with two retractable levers located on either side of a drinking reservoir $(0.1 \mathrm{ml})$ positioned in the center of the front panel of the chamber. The levers were counterbalanced for responding as the active lever (delivering $0.1 \mathrm{ml}$ of $10 \%$ alcohol w/v solution) or as the inactive lever. Once animals had acquired stable responding for $\mathrm{EtOH}$, the inactive lever was presented. Groups were matched based on the week of baseline and the first week of alcohol reinstatement. The number of responses and dipper presentations in both levers were registered automatically by computer software. The content of the dipper was accessible to the animal until the next lever press with a $2.5 \mathrm{sec}$ interval to avoid measuring dipper presentations as lever presses.

CPP and locomotor activity. The rewarding or aversive effects of WIN 55,212-2 were evaluated using the CPP paradigm in a three-arm apparatus, as described previously (Rubio et al., 1998). The apparatus consisted of three interconnected rectangular boxes of $40 \times 35 \times 35 \mathrm{~cm}$ situated at angles of $120^{\circ}$ from each other. In the center, there was a triangular area with a smooth glass floor from which any of the three compartments were accessible. Each compartment was equipped with a set of different sensory stimuli. Compartment A was equipped with plain gray walls. Compartment $\mathrm{B}$ had the walls painted with white dots $(7.5 \mathrm{~cm})$. Compartment $\mathrm{C}$ had alternating white stripes ( $5 \mathrm{~cm}$ wide) painted on the walls. After each testing procedure, the floors were washed to avoid odor cues.

The CPP experiment consisted of a $7 \mathrm{~d}$ schedule with a preconditioning, a conditioning, and a testing phase. In the preconditioning phase, the animals were allowed to explore compartments A, B, and C freely for 20 min. Animals exhibiting strong unconditioned aversion (10\% of the session) or preference ( $60 \%$ of the session) for any compartment were discarded for the conditioning procedures. In the present experiment, however, none of the animals were discarded. The two compartments to which the animals exhibited the most similar time of preference were counterbalanced and assigned for the conditioning procedure. The conditioning phase consisted of a $5 \mathrm{~d}$ schedule of double-conditioning sessions, a morning (9:00 A.M. to 1:00 P.M.) and an evening (3:00 P.M. to 7:00 P.M.) session. The sessions were completely counterbalanced, morning-evening and WIN 55,212-2-vehicle sessions. The animals received a single dose of WIN 55,212-2 subcutaneously (0.0, 0.4, 2.0, and $10.0 \mathrm{mg} / \mathrm{kg}$ ) or vehicle and were immediately placed in one of the compartments. During the $30 \mathrm{~min}$ conditioning sessions, the animals were not allowed to explore any of the remaining compartments. In the testing phase, the animals again were allowed to explore freely the three compartments during $20 \mathrm{~min}$ as in the preconditioning step. The absolute time spent in each compartment was automatically registered and used for the evaluation of the CPP. Each compartment of the apparatus was equipped with eight photocells to monitor the position of the animal and to register the time spent in each compartment without human intervention.

The locomotor responses induced by WIN 55,212-2 or vehicle were evaluated in the compartments of the CPP apparatus. Each box contained two lines of four photocells (as mentioned above), 4 and $8 \mathrm{~cm}$ above the floor. This activity was recorded during the $30 \mathrm{~min}$ conditioning phase after WIN 55,212-2 or vehicle administration. The animals were always weighed immediately before the start of the session (selfadministration or CPP trial).

Data analysis. Data from the CPP paradigm were analyzed by repeated-measures ANOVA, with preconditioning and postconditioning day as the within-subjects factor and different doses of WIN 55,212-2 as the between-groups factor. Data from locomotor activity were analyzed by repeated-measures ANOVA, with days one to five as the withinsubjects factor and different doses of WIN 55,212-2 as the betweengroups factor. Data from weekly ethanol operant self-administration were analyzed by a three-way ANOVA with repeated measures on two factors (week 1 and week 2 and presence and absence of the cannabinoid effect during the week) and one factor between groups (different doses of WIN 55,212-2). Data from daily ethanol self-administration and body weight during alcohol relapses were analyzed by a three-way ANOVA, as 
mentioned above. Data from daily body weight during WIN 55,212-2 treatment were analyzed by repeated-measures ANOVA (statistics were done on percentages). Only significant effects ( $p$ values $<0.05)$ in ANOVA analysis were subjected to Tukey's honestly significant difference test (between-groups factor) and the post hoc analysis for repeated measures subprogram of the Statistical Program for the Social Sciences (SPSS, Chicago, IL) statistical software package (version 11.0) for Windows.

\section{Results}

\section{Ethanol self-administration}

The response obtained in EtOH self-administration after a single alcohol deprivation period or after exposure to WIN 55,212-2 concomitantly with alcohol deprivation is shown in Figure 1. There were statistically significant interactions between the presence-absence of cannabinoid effect in the week and different doses of WIN 55,212-2 $\left(F_{(3,41)}=4.97 ; p<0.005\right)$ and between week 1 -week 2 and presence-absence of cannabinoid effect in the week $\left(F_{(1,41)}=5.86 ; p<0.02\right)$, whereas a significant interaction between the three factors, week 1-week 2, presence-absence of cannabinoid effect in the week, and different doses of WIN $55,212-2$, was not observed $\left(F_{(3,41)}=1.25 ; p<0.31\right)$. On the other hand, a significant interaction between week 1-week 2 and doses of WIN 55,212-2 was not found $\left(F_{(3,41)}=0.21 ; p<0.90\right)$. However, the weekly EtOH responding in rats exposed to WIN 55,212 -2 was enhanced significantly compared with baseline levels (within-subjects ANOVA, $F_{(1,41)}=54.83$, $p<0.0001$; interaction between different doses of WIN 55,212-2 and week

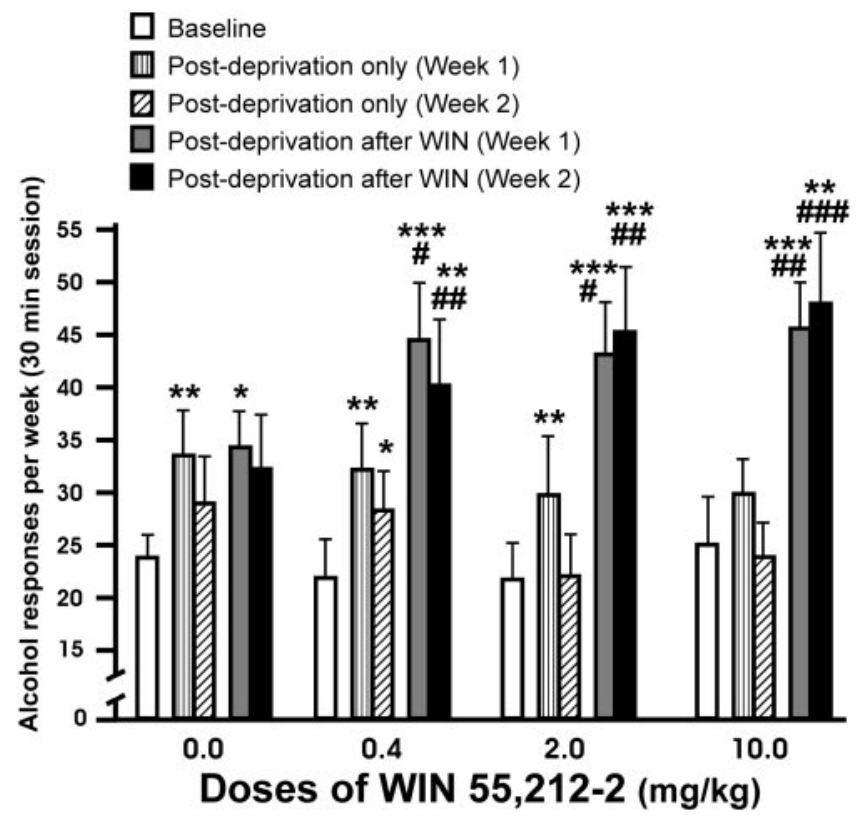

Figure 1. Effects in relapse to alcohol after a single alcohol deprivation period (hatched bars) and relapse to alcohol after WIN 55,212-2 treatment during alcohol deprivation (filled bars). Doses of WIN 55,212-2 are in milligrams/kilogram. These data represent the responses for alcohol by day ( 30 min session) averaged over a 1 week period. Asterisks indicate statistically significant differences between baseline and increases in ethanol responding in the first and second weeks postdeprivation after $7 \mathrm{~d}$ of ethanol deprivation. The groups treated with WIN 55,212-2 showed a significantly higher increase and persistent responding for alcohol during the second week. \# symbols indicate statistically significant differences between the first and second week of alcohol relapse after a single alcohol deprivation and their corresponding first and second week of alcohol relapse after an alcohol deprivation period concomitant with WIN $55,212-2$. Only the animals treated with this cannabinoid receptor agonist showed statistically significant differences. Values are expressed as mean \pm SEM of responding for alcohol by weeks. ${ }^{*} p<0.05 ;{ }^{* *} p<0.01 ;{ }^{* * *} p<0.001 ;{ }^{\#} p<0.05 ;{ }^{\# \#} p<0.01 ;{ }^{\# \# \#} p<0.001$. 1-week 2, $F_{(3,41)}=2.05, p=0.12$, NS; different doses of WIN $\left.55,212-2, F_{(1,3)}=0.18, p=0.91, \mathrm{NS}\right)$. The subsequent withinsubjects post hoc test for repeated measures showed a temporary increase in alcohol responding in the vehicle group only in the first week of alcohol relapse $\left({ }^{*} p<0.01 ;{ }^{* *} p<0.01\right.$; ${ }^{* * *} p<$ $0.001)$. In contrast, alcohol intake was significantly higher and persistent throughout 2 weeks in animals exposed to WIN $55,212-2$. When the first and second week of alcohol relapse without pretreatment during the alcohol deprivation period were compared with their corresponding first and second weeks of alcohol relapse but with pretreatment with WIN 55,212-2 during alcohol deprivation, statistically significant differences were only obtained in the groups pretreated with the cannabinoid agonist $\left({ }^{\#} p<0.01 ;{ }^{\# \#} p<0.0 ;{ }^{\# \#} p<0.001\right)$.

The day-by-day time course of alcohol responding after a single week of alcohol abstinence versus the same period of abstinence but with WIN 55,212-2 treatment was then examined (Fig. 2). After treatment with WIN 55,212-2, the animals exhibited a significantly different pattern and higher consumption of EtOH compared with their own postdeprivation period without the cannabinoid agonist (three-way ANOVA, interaction between presence-absence of cannabinoid effect, days, and different doses of WIN 55,212-2, $F_{(3,41)}=3.41, p=0.054$, NS; interaction between presence-absence of cannabinoid effect and days, $F_{(1,41)}=$ 5.31, $p<0.05$; interaction between days and different doses of WIN 55,212-2, $F_{(3,41)}=0.74, p=0.53$, NS; interaction between presence-absence of cannabinoid effect and doses of WIN $55,212-2, F_{(3,41)}=5.31, p<0.005$; effect of presence-absence of the cannabinoid effect, $F_{(1,41)}=55.12, p<0.0001$; effect of days, $\left.F_{(1,41)}=24.52, p<0.0001\right)$. Notably, the subsequent withinsubjects post hoc test for repeated measures showed that this enhancement and maintenance in the amount of responding for ethanol was more pronounced for the highest dose of WIN $55,212-2$. Pretreatment with $0.4 \mathrm{mg} / \mathrm{kg}$ during alcohol deprivation period resulted in significant differences of EtOH consumption during $4 \mathrm{~d}$ compared with $\mathrm{EtOH}$ consumption without pretreatment $\left({ }^{*} p<0.05\right)$, whereas significant differences were observed for $8 \mathrm{~d}$ with the dose of $10.0 \mathrm{mg} / \mathrm{kg}\left({ }^{\star} p<0.05\right.$; ${ }^{\star *} p<$ $\left.0.01 ;{ }^{* *} p<0.001\right)$. However, significant differences in responding for ethanol in the vehicle group were not observed. Finally, Figure 3 shows the pattern of alcohol reinforcement obtained during the $30 \mathrm{~min}$ session (at 5 min intervals) in three representative days, the last day of baseline and the first and fifth day of alcohol relapse after treatment with WIN 55,212-2 or vehicle. The vehicle group reached the baseline level of alcohol reinforcement at the fifth day of alcohol reinstatement, whereas the groups pretreated with 0.4 and $2.0 \mathrm{mg} / \mathrm{kg}$ WIN 55,212-2 showed a persistent increase compared with baseline. Interestingly, the dose of 10.0 $\mathrm{mg} / \mathrm{kg}$ WIN 55,212-2 showed an opposite pattern in relation to the vehicle group, with the highest number of alcohol reinforcements on day 5 and similar reinforcement levels to baseline on day 1 . Statistically significant differences refer to the previous baseline data of the rats $\left({ }^{\star} p<0.05 ;{ }^{\star *} p<0.01\right)$.

\section{CPP and locomotor activity}

WIN 55,212-2-induced CPP and locomotor activity were evaluated during EtOH deprivation. Figure 4 shows the difference in time spent in the compartment paired with WIN 55,212-2, the vehicle, or not paired with any substance between the preconditioning and postconditioning day. We found an aversive effect that is expressed as a shorter time spent in the postconditioning day compared with the preconditioning day in all the compartments associated with WIN 55,212-2 (within-subjects ANOVA, 
$F_{(1,41)}=31.89, p<0.0001$; interaction between days and treatment, $F_{(3,41)}=4.71$, $p<0.01$; between groups, $F_{(3,41)}=0.68$, $p=0.57, \mathrm{NS})$. Furthermore, the aversive effect was also reflected in the vehicleassociated compartment but, in this case, expressed as greater time spent in this compartment (i.e., the animal avoided the compartment paired with the drug) (within-subjects ANOVA, $F_{(1,41)}=6.02$, $p<0.05$; interaction between days and treatment, $F_{(3,41)}=0.92, p=0.44$, NS; between groups, $F_{(3,41)}=1.02, p=0.39$, NS). In contrast, in the compartment not paired with either WIN 55,212-2 or vehicle, there were no significant differences in the time spent during the preconditioning and postconditioning sessions (withinsubjects ANOVA, $F_{(1,41)}=2.68, p=0.11$, NS; interaction between days and treatment, $F_{(3,41)}=0.34, p=0.80$, NS; between groups, $F_{(3,41)}=1.02, p=0.39$, NS). The ANOVAs showing significant differences $(p<0.05)$ were followed only by withinsubjects post hoc test for repeated measures because there were not any significant differences between groups.

The effects of WIN 55,212-2 on locomotor activity during the ethanol deprivation period are depicted in Figure 5. The counts of photocell crossings during 30 min on 5 consecutive days during the WIN 55,212-2 and vehicle conditioning sessions in the CPP protocol are shown in Figure 5, $a$ and $b$, respectively (withinsubjects ANOVA, $F_{(1,38)}=61.35, p<$ 0.0001 ; interaction between days and

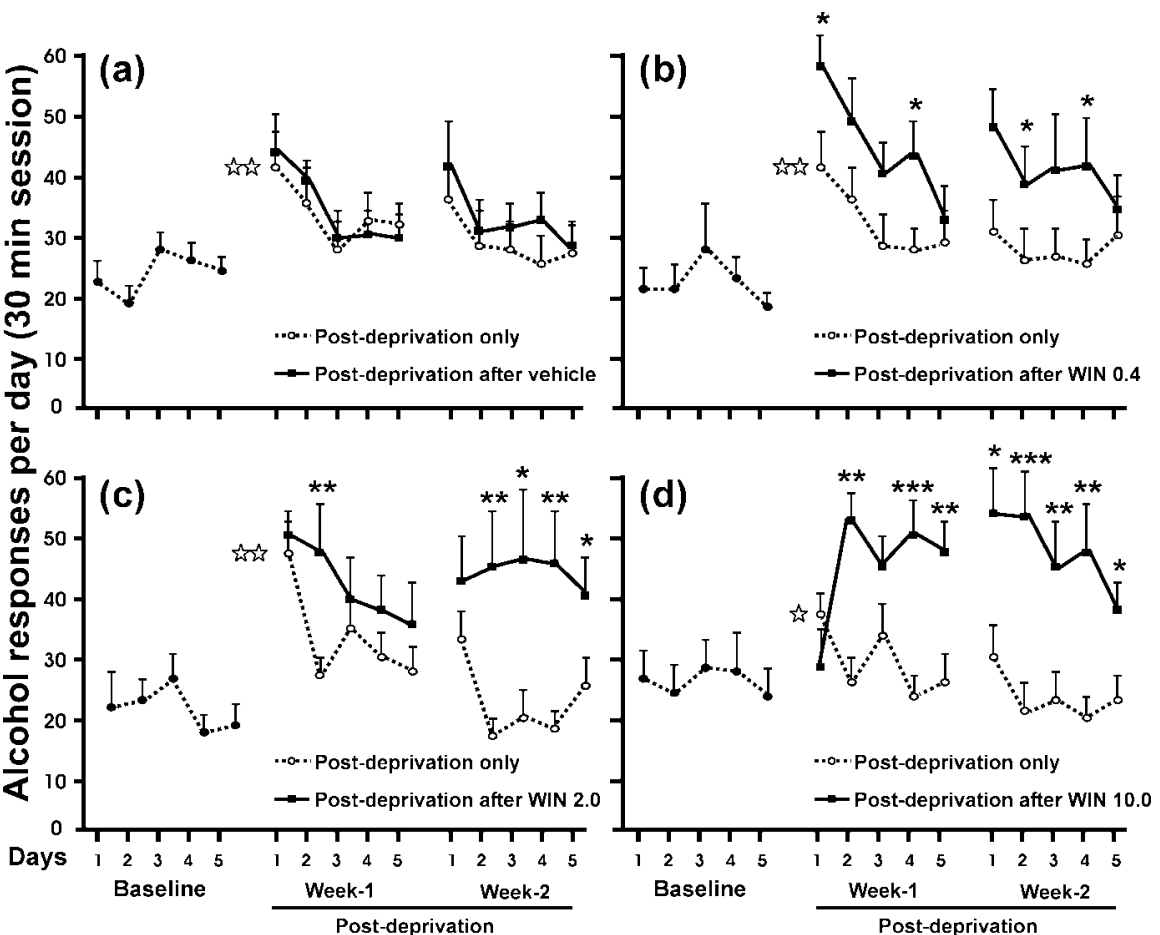

Figure 2. Effects in relapse to alcohol after a single alcohol deprivation period (dotted lines, open circles) and relapse to alcohol after WIN 55,212-2 treatment during alcohol deprivation (black lines, filled squares). Doses of WIN 55,212-2 are in milligrams/ kilogram. These data represent the responses for alcohol (30 min session) for 5 consecutive days with a 1 week interval between baseline and postdeprivation period and $2 \mathrm{~d}$ interval between week 1 and week 2 of the postdeprivation period. Black asterisks show the statistically significant differences between the first and second week of alcohol relapse after a single alcohol deprivation and their corresponding first and second week of alcohol relapse after an alcohol deprivation period concomitant with WIN 55,212-2. Only the animals treated with WIN 55,212-2 showed statistically significant differences. Differences were not significant in the vehicle group. With the highest dose of WIN $55,212-2(10.0 \mathrm{mg} / \mathrm{kg})(d)$, the responding for alcohol seemed to be blocked on the first day of relapse after treatment but abruptly increased on the second day of relapse and was maintained during 2 weeks. White asterisks represent significant differences on day 1 for WIN and saline groups compared with their corresponding baseline values (alcohol deprivation effect). Values are expressed as mean \pm SEM of responding for alcohol by days. ${ }^{*} p<0.05$; ${ }^{* *} p<$ $0.01 ;{ }^{* * *} p<0.001$.

treatment, $F_{(3,38)}=4.54, p=0.01$; between groups, $\left.F_{(3,38)}=12.90, p<0.0001\right)$. The Tukey's post hoc tests between groups, day-by-day, were used to discriminate the effects of treatment, day-by-day. The administration of WIN 55,212-2 dose-dependently suppressed the locomotor activity $\left.{ }^{\star} p<0.05 ;{ }^{* *} p<0.01 ;{ }^{* *} p<0.001\right)$. Rats treated with the doses of 2.0 and $10.0 \mathrm{mg} / \mathrm{kg}$ WIN 55,212-2 showed significantly suppressed spontaneous activity, but animals treated with $0.4 \mathrm{mg} / \mathrm{kg}$ or vehicle did not. Additionally, a different pattern of counts of photocell crossings during the first exposure to WIN 55,212-2 in 30 min were observed (data not shown) (within-subjects ANOVA, $F_{(1,38)}=43.72, p<0.0001$; interaction between days and treatment, $F_{(3,38)}=1.52, p=0.23$, NS; between groups, $\left.F_{(3,38)}=3.32, p<0.05\right)$. This effect was fully evident on the first $10 \mathrm{~min}$ and persisted throughout the conditioning session. However, only with the highest dose of WIN 55,212-2, some motor residual effects were present during the vehicle sessions (withinsubjects ANOVA, $F_{(1,38)}=21.64, p<0.0001$; interaction between days and treatment, $F_{(3,38)}=9.74, p<0.0001$; between groups, $\left.F_{(3,38)}=12.41, p<0.0001\right)$.

\section{Animal weight}

Dose-dependent weight loss during WIN 55,212-2 treatment is shown in Figure $6 b$. Data are expressed as mean \pm SEM percentages (within-subjects ANOVA, $F_{(1,41)}=89.45, p<0.0001$; interaction between days and different doses of WIN 55,212-2, $F_{(3,41)}$
$=36.93, p<0.0001$; between different doses of WIN 55,212-2, $\left.F_{(3,41)}=14.77, p<0.001\right)$. The Tukey's post hoc tests revealed that there were no statistically significant differences between groups only in the first day of treatment. Figure $6, a$ and $c$, shows that weight loss was persistent throughout the following 2 weeks to cannabinoid treatment, whereas during the 2 weeks after a single alcohol deprivation, the mean weight showed no significant differences (three-way ANOVA; interaction between the three factors presence-absence of the cannabinoid effect, days, and different doses of WIN 55,212-2, $F_{(3,41)}=1.89, p=0.15$, NS; interaction between presence-absence of the cannabinoid effect and days, $F_{(1,41)}=0.47, p=0.83$, NS; interaction between days and different doses of WIN 55,212-2, $F_{(3,41)}=1.22, p=0.32$, NS; interaction between presence-absence of the cannabinoid effect and different doses of WIN 55,212-2, $F_{(3,41)}=41.67, p<0.00001$; presence-absence of the cannabinoid effect, $F_{(1,41)}=0.38, p<$ 0.54 , NS; effect of days, $\left.F_{(1,41)}=81.73, p<0.00001\right)$. The Tukey's post hoc analysis showed that the doses of WIN 55,212-2 of 0.2 and $10.0 \mathrm{mg} / \mathrm{kg}$ were significantly different between the vehicle and $0.4 \mathrm{mg} / \mathrm{kg}$-treated groups $\left({ }^{\star} p<0.05 ;{ }^{* *} p<0.01\right.$; ${ }^{\star * *} p<$ $0.001)$.

\section{Discussion}

The four main findings of this study are as follows: (1) the cannabinoid agonist WIN 55,212-2 induced conditioned place aver- 


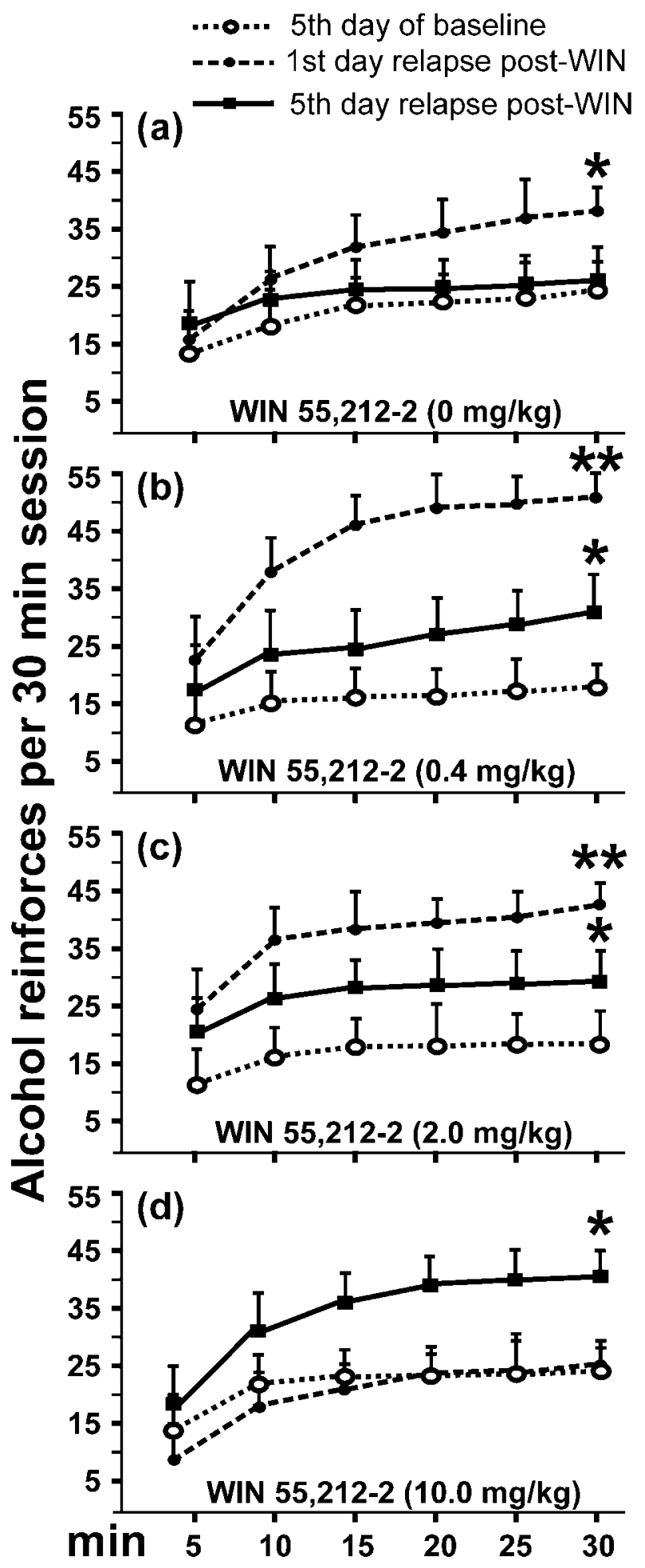

Figure 3. Changes in the cumulative reinforcements obtained (30 min session, at 5 min intervals) by the rats during 3 representative days: the last day of baseline (dotted lines, open circles), the first day of alcohol relapse (dotted lines, filled circles), and the fifth day of alcohol relapse (black lines, filled squares) after vehicle or WIN 55,212-2 treatment (doses are in milligrams/kilogram). Asterisks show statistically significant differences compared with baseline. As can be seen, the vehicle group reached its baseline level of alcohol reinforcements at the fifth day of alcohol reinstatement. The groups pretreated with 0.4 and $2.0 \mathrm{mg} / \mathrm{kg}$ WIN 55,212-2 showed a persistent increase compared with baseline. The dose of $10.0 \mathrm{mg} / \mathrm{kg}$ WIN 55,212-2 showed an opposite pattern in relation to the vehicle group; the greatest number of alcohol reinforcements occurred on the fifth day, whereas similar reinforcing levels compared with baseline was obtained on the first day. Values are expressed as mean \pm SEM of reinforcements obtained during three different sessions. ${ }^{*} p<0.05 ;{ }^{* *} p<0.01$.

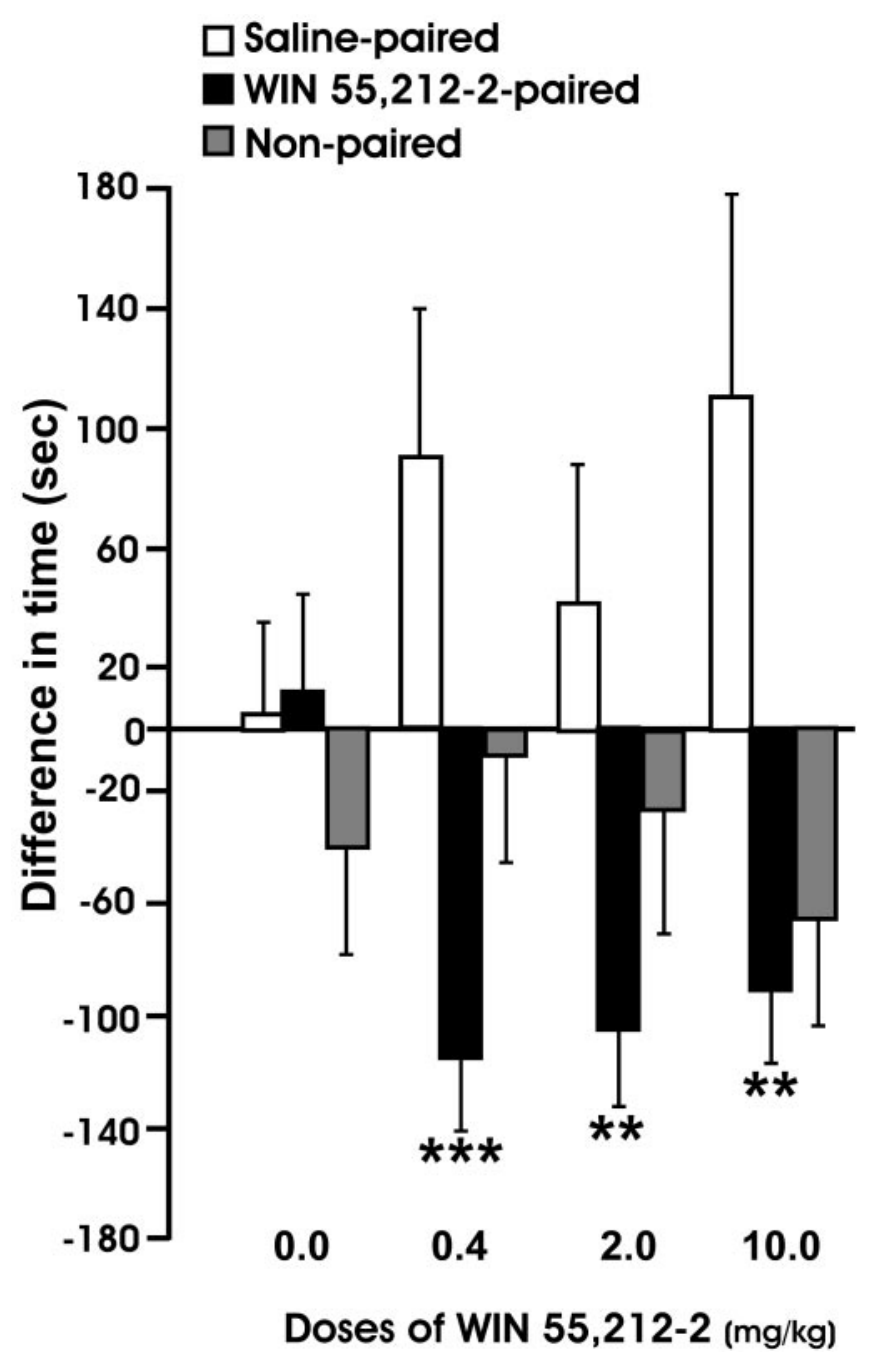

Figure 4. Change in compartment preference after $5 d$ of exposure to WIN 55,212-2 or vehicle. This parameter is expressed as the difference in seconds spent in each compartment associated with WIN 55,212-2 (0.2, 2.0, and $10.0 \mathrm{mg} / \mathrm{kg}$, s.c.), vehicle, or nonpaired compartment between the preconditioning and postconditioning day. The score was calculated by subtracting the time spent by the animal in each compartment in the preconditioning session from the time spent in the same compartment in the postconditioning session. Values are mean seconds \pm SEM. Data were analyzed by repeated-measures ANOVA and followed by the corresponding post hoc analysis for repeated measures. ${ }^{* *} p<0.01$; ${ }^{* * *} p<0.001$.

sion; (2) WIN 55,212-2 suppressed spontaneous locomotor activity given at doses of 2.0 and $10.0 \mathrm{mg} / \mathrm{kg}$; (3) animals experienced a significant weight loss during treatment with the doses of 2.0 and $10.0 \mathrm{mg} / \mathrm{kg}$ of the cannabinoid agonist and during the following $14 \mathrm{~d}$; and (4) rats with an extended background of EtOH self-administration and treated with WIN 55,212-2 during alcohol deprivation showed a long-lasting increase in their responding for alcohol. In contrast, when the animals passed periods of abstinence only from alcohol, they only showed a temporary increase in their EtOH consumption. This last finding is in agreement with most studies (Heyser et al., 1998, 2003; RoddHenricks et al., 2000; Samson et al., 2001; Serra et al., 2002; Cowen et al., 2003; Vengeliene et al., 2003).

In our study, like others (McGregor et al., 1996; Sañudo-Peña et al., 1997; Chaperon et al., 1998), the cannabinoid agonist WIN $55,212-2$ induced aversion in the CPP paradigm at all doses tested $(0.4,2.0$, and $10.0 \mathrm{mg} / \mathrm{kg}$ ) (Fig. 4). This effect was not dose dependent, although the greatest statistically significant difference 


\section{Locomotor activity}

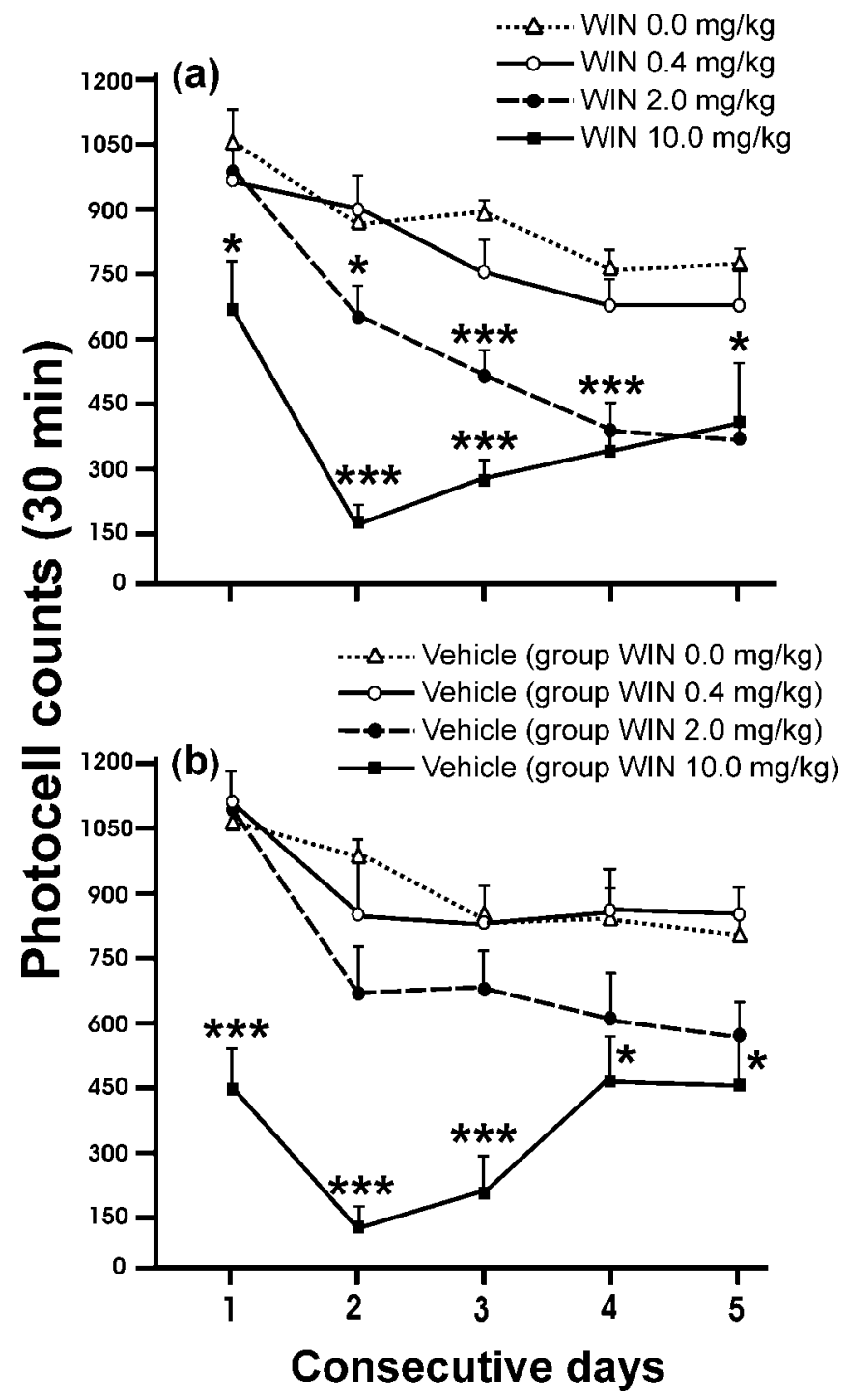

Figure 5. Photocell counts of locomotor activity during the 5 consecutive days of WIN $55,212-2$ or vehicle treatment (a total of 10 conditioning sessions). The rats were placed into the compartments immediately after treatment, and their activity was registered throughout the following $30 \mathrm{~min}$. The effects of WIN 55,212-2 or vehicle on locomotor activity are shown in $a$ and $b$, respectively. The hypolocomotor effects observed in the saline sessions with the highest dose of WIN 55,212-2 were caused by the long half-life of WIN 55,212-2. Values are expressed as mean \pm SEM. Data were first analyzed by repeated-measures ANOVA, followed by Tukey's post hoc test for contrast between groups. ${ }^{*} p<0.05$; ${ }^{* * *} p<0.001$ when compared with the vehicle group.

was observed with the lowest WIN 55,212-2 dose $(0.4 \mathrm{mg} / \mathrm{kg})$. One likely explanation is that the higher the dose of WIN $55,212-2$, the greater the impairment of the acquisition of a spatial memory. The influence of cannabinoids on memory is well documented (Lichtman and Martin, 1996; Mallet and Beninger, 1998; Braida and Sala, 2000). Cannabinoids, as well as other drugs of abuse such as nicotine and cocaine, induce aversion in the CPP paradigm. However, this contrasts with the rewarding properties that can be observed with the use of these drugs in different paradigms (Jorenby et al., 1990; Koob, 1992; Fidler et al., 2004).

Also, the hypoactivity and, in some cases, the catalepsy after cannabinoid treatment has been described (Pertwee, 1974;
Hutcheson et al., 1998; Chaperon and Thiebot, 1999). The important decrease in photocell counts with 2.0 and $10.0 \mathrm{mg} / \mathrm{kg}$ WIN 55,212-2, indicating depressed spontaneous locomotor activity (Fig. 5), would be in agreement with these previous reports.

WIN 55,212-2 produces a long-lasting increase of the alcohol deprivation effect. The alcohol deprivation effect is a useful model for monitoring alcohol relapse. In this study, we used male Wistar rats, which have been shown to develop the alcohol deprivation effect (Hölter et al., 1996; Spanagel et al., 1996; Heyser et al., 1998, 2003). However, rats exposed to WIN 55,212-2 showed a persistent increase in responding for alcohol (over 2 weeks), abolishing the characteristic temporality of increase of alcohol intake of the alcohol deprivation effect (Figs. 1-3). This fact, in contrast to the alcohol deprivation effect of 1 or $2 \mathrm{~d}$ duration, was illustrated by the significant differences in the total amount of EtOH consumed. Unexpectedly, with the highest dose of WIN $55,212-2(10.0 \mathrm{mg} / \mathrm{kg})$, alcohol self-administration seemed to be blocked on the first day of alcohol relapse. As has been already mentioned, this effect could be explained by memory impairment (Davies et al., 2002) induced by cannabinoids because hypolocomotor effects were absent. However, a rapid enhancement and constant responding for alcohol from the second day of reinstatement was observed.

On the other hand, numerous experimental studies have revealed the role of the cannabinoid $\mathrm{CB}_{1}$ receptor in the increase in voluntary EtOH consumption (Gallate et al., 1999; Colombo et al., 2002). However, it should be noted that, in our study, the exposure to WIN 55,212-2 was throughout the alcohol abstinence period, avoiding simultaneous exposure to both drugs (alcohol and cannabinoid). The animals were reintroduced into EtOH operant chambers on the third day after the last injection. Any conditioned response was excluded because treatment with WIN 55,212-2 was given in a different context (CPP apparatus). These results imply that the contingency of both drugs is not necessary to reveal cannabinoid-mediated alcohol consumption. To our knowledge, these results constitute the first behavioral data demonstrating the interaction between the cannabinoid system and alcohol consumption without any contingency of both drugs. Thus, these observations may indicate that long-lasting changes in the cannabinoid system through the $\mathrm{CB}_{1}$ receptor could be shifting the responding for alcohol after exposure to cannabinoids. It is likely that one of these changes is mainly the downregulation of the $\mathrm{CB}_{1}$ receptor.

To understand these changes, two aspects should be taken into account. First, we used animals treated chronically with the cannabinoid agonist WIN 55,212-2, which could be downregulating the $\mathrm{CB}_{1}$ receptor (Breivogel et al., 2003), in particular when the moderate $(2.0 \mathrm{mg} / \mathrm{kg})$ and the highest $(10.0 \mathrm{mg} / \mathrm{kg})$ doses were used. Second, the rats had an extended history of alcohol self-administration of at least 8 weeks. In baseline, the blood alcohol concentrations that can be reached by Wistar rats responding for alcohol (30 min session) have been estimated between 25 and $30 \mathrm{mg} \%$, whereas higher levels of responding after withdrawal have been associated between 40 and $80 \mathrm{mg} \%$ (Roberts et al., 1999). Interestingly, chronic EtOH exposure can also cause a downregulation of the $\mathrm{CB}_{1}$ receptor function and its signal (Basavarajappa and Hungund, 2002), but, as far as we are aware, it has been only demonstrated with higher blood alcohol concentrations in a $4 \mathrm{~d}$ period of exposure to EtOH (Basavarajappa and Hungund, 1999). Accordingly, it may be expected that the long-lasting increase found in the responding for alcohol in our study may be mediated, at least in part, by an important dysfunction of the $\mathrm{CB}_{1}$ receptor. Additionally, the animals in our 


\section{.0.. Vehicle $0.0 \mathrm{mg} / \mathrm{kg} \quad$..•. WIN $2.0 \mathrm{mg} / \mathrm{kg}$ \\ WIN $0.4 \mathrm{mg} / \mathrm{kg}$ \\ WIN $10.0 \mathrm{mg} / \mathrm{kg}$}

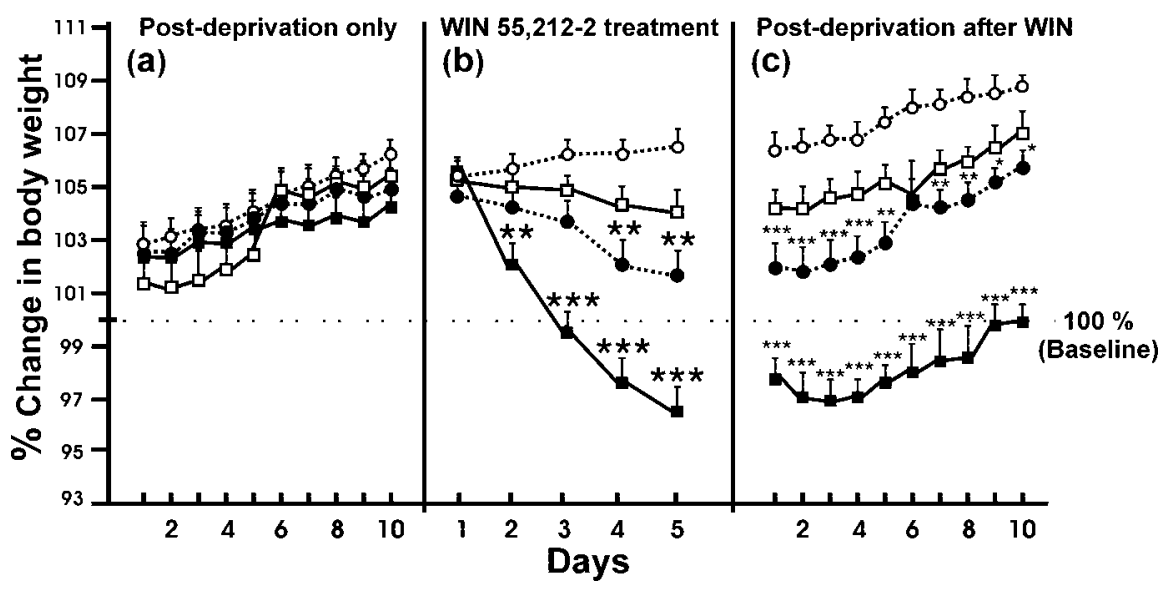

Figure 6. Changes in animals' weight during the 2 weeks of alcohol relapse after a single alcohol deprivation period $(a)$, during the $5 \mathrm{~d}$ of the treatment with the agonist cannabinoid WIN 55,212-2(b), and during the 2 weeks of alcohol relapse after WIN 55,212-2 treatment in alcohol deprivation period ( $(c)$. The animals' weight (mean, $402 \mathrm{gm} \pm$ SEM) from the week of the establishment of baseline was used as $100 \%$ of weight. Data were analyzed by percentage. ${ }^{*} p<0.05$; ${ }^{* *} p<0.01$; ${ }^{* * *} p<0.001$, different from vehicle (Tukey's post hoc tests analysis after between-groups ANOVA).

study had an intermittent access to alcohol, Monday to Friday and two periods of EtOH deprivation. It has been demonstrated that gene expression changes 3 weeks after intermittent exposure to alcohol during 7 weeks. These changes include an increase in $\mathrm{CB}_{1}$ receptor mRNA in medial prefrontal (cingulate) cortex (Rimondini et al., 2002). We believe that the model of intermittent access to alcohol is valid because, in human beings, alcohol may not be available at all times (compared with alcohol continuous-access paradigm).

It may be also considered that the long-lasting increase in the responding for alcohol is caused by spontaneous cannabinoid withdrawal after chronic exposure to WIN 55,212-2. Recently, Aceto et al. (2001) showed a modest spontaneous withdrawal after a $4 \mathrm{~d}$ chronic treatment with WIN 55,212-2. This effect was visible at $24 \mathrm{hr}$. In the present protocol, the animals had access to $\mathrm{EtOH}$ on the third day after the last injection. However, according to these authors (Aceto et al., 2001) and more pronouncedly, we found a significant weight loss in the rats with the doses of 2.0 and $10.0 \mathrm{mg} / \mathrm{kg}$ (Fig. 6). Other studies have highlighted a loss of weight as a clear sign of cannabinoid withdrawal (Jones et al., 1981; Budney et al., 2001; Anggadiredja et al., 2003). In addition, spontaneous cannabinoid withdrawal has been described for 72 hr after CP-55,940 treatment in mice (Oliva et al., 2003), producing alterations in gene transcription such as increased proopiomelanocortin (POMC) gene expression. POMC has been implicated in the regulation of alcohol dependence, alcohol relapse, and the alcohol deprivation effect (Rasmussen et al., 2002). Given these data, the long-term increase in alcohol consumption would be an indirect manifestation of a spontaneous withdrawal from cannabinoids, although other causes and additional effects cannot be discarded, including possible nonspecific effects of the WIN 55,212-2 compound at the highest dose used.

Alternatively, persistent alterations (up to 2 weeks) in dopamine and serotonin neurotransmission in the nucleus accumbens of alcohol-preferring rats have been reported (Thielen et al., 2004). In this line, it has been proposed that the excessive and persistent increase in EtOH intake is caused by an elevation in the ethanol reward set point or threshold for ethanol reward, the allostasis hypothesis (Koob and Le Moal 1997; Roberts et al., 2000). Importantly, Roberts et al. (2000) have found similar persistent operant responding for alcohol during reinstatement, but in this case using ethanol-dependent animals (1 month in EtOH vapor chambers). These data may suggest that exposure to the cannabinoid WIN 55,212-2 during abstinence from $\mathrm{EtOH}$ can reproduce effects that can only be seen in alcohol-dependent animals, indicating that alterations in the cannabinoid system could be causing an important regulation of alcohol addiction.

In conclusion, exposure to the cannabinoid agonist WIN 55,212-2 during alcohol deprivation, with noncontingent administration, produced a long-lasting increase in the responding for alcohol. We suggest that functional alterations in the $\mathrm{CB}_{1}$ receptor after chronic treatment with WIN 55,212-2, together with intermittent access to alcohol, would be involved in the mechanism underlying the long-term change in the hedonic set point for alcohol. The protocol used illustrates a pattern of consumption very often found in human individuals (Rodríguez and Anglin, 1988; Chung et al., 2004). It has been demonstrated to be a useful model for studying some components of the multifaceted alcoholismaddiction, such as vulnerability, craving, and relapse, which are the principal factors perpetuating alcohol consumption.

\section{References}

Aceto MD, Scates SM, Martin BB (2001) Spontaneous and precipitated withdrawal with a synthetic cannabinoid, WIN 55212-2. Eur J Pharmacol 416:75-81.

Anggadiredja K, Yamaguchi T, Tanaka H, Shoyama Y, Watanabe S, Yamamoto $T$ (2003) Prostaglandin $E_{2}$ attenuates SR141716Aprecipitated withdrawal in tetrahydrocannabinol-dependent mice. Brain Res 966:47-53.

Basavarajappa BS, Hungund BL (1999) Down-regulation of cannabinoid receptor agonist-stimulated [35S]GTP gamma S binding in synaptic plasma membrane from chronic ethanol exposed mouse. Brain Res 815:89-97.

Basavarajappa BS, Hungund BL (2002) Neuromodulatory role of the endocannabinoid signaling system in alcoholism: an overview. Prostaglandins Leukot Essent Fatty Acids 66:287-299.

Braida D, Sala M (2000) Cannabinoid-induced working memory impairment is reversed by a second generation cholinesterase inhibitor in rats. NeuroReport 11:2025-2029.

Breivogel CS, Scates SM, Beletskaya IO, Lowery OB, Aceto MD, Martin BR (2003) The effects of delta9-tetrahydrocannabinol physical dependence on brain cannabinoid receptors. Eur J Pharmacol 459:139-150.

Budney AJ, Hughes JR, Moore BA, Novy PL (2001) Marijuana abstinence effects in marijuana smokers maintained in their home environment. Arch Gen Psychiatry 58:917-924.

Chaperon F, Thiebot MH (1999) Behavioral effects of cannabinoid agents in animals. Crit Rev Neurobiol 13:243-281.

Chaperon F, Soubrie P, Puech AJ, Thiebot MH (1998) Involvement of central cannabinoid (CB1) receptors in the establishment of place conditioning in rats. Psychopharmacology 135:324-332.

Chung T, Maisto SA, Cornelius JR, Martin CS (2004) Adolescents' alcohol and drug use trajectories in the year following treatment. J Stud Alcohol 65:105-114.

Colombo G, Serra S, Brunetti G, Gómez R, Melis S, Vacca G, Carai MM, Gessa GL (2002) Stimulation of voluntary ethanol intake by cannabinoid receptor agonists in ethanol-preferring sP rats. Psychopharmacology 159:181-187. 
Colombo G, Serra S, Brunetti G, Vacca G, Carai MA, Gessa GL (2003) Suppression by baclofen of alcohol deprivation effect in Sardinian alcoholpreferring (sP) rats. Drug Alcohol Depend 70:105-108.

Cowen MS, Schroff KC, Gass P, Sprengel R, Spanagel R (2003) Neurobehavioral effects of alcohol in AMPA receptor subunit (GluR1) deficient mice. Neuropharmacology 45:325-333.

Davies SN, Pertwee RG, Riedel G (2002) Functions of cannabinoid receptors in the hippocampus. Neuropharmacology 42:993-1007.

Fidler TL, Bakner L, Cunningham CL (2004) Conditioned place aversion induced by intragastric administration of ethanol in rats. Pharmacol Biochem Behav 77:731-743.

Gallate JE, Saharov T, Mallet PE, McGregor IS (1999) Increased motivation for beer in rats following administration of a cannabinoid CB1 receptor agonist. Eur J Pharmacol 370:233-240.

Heyser JC, Schulteis G, Durbin P, Koob GF (1998) Chronic acamprosate eliminates the alcohol deprivation effect while having limited effects on baseline responding for ethanol in rats. Neuropsychopharmacology 18:125-133.

Heyser JC, Moc K, Koob GF (2003) Effects of naltrexone alone and in combination with acamprosate on the alcohol deprivation effect in rats. Neuropsychopharmacology 28:1463-1471.

Hölter SM, Danysz W, Spanagel R (1996) Evidence for alcohol anti-craving properties of memantine. Eur J Pharmacol 314:R1-R2.

Hungund BL, Szakall I, Adam A, Basavarajappa BS, Vadasz C (2003) Cannabinoid CB1 receptor knockout mice exhibit markedly reduced voluntary alcohol consumption and lack alcohol-induced dopamine release in the nucleus accumbens. J Neurochem 84:698-704.

Hutcheson DM, Tzavara ET, Smadja C, Valjent E, Roques BP, Hanoune J, Maldonado R (1998) Behavioural and biochemical evidence for signs of abstinence in mice chronically treated with delta-9-tetrahydrocannabinol. Br J Pharmacol 125:1567-1577.

Jones RT, Benowitz NL, Herning RI (1981) Clinical relevance of cannabis tolerance and dependence. J Clin Pharmacol 21 [Suppl 8-9]:143S-152S.

Jorenby DE, Jorenby DE, Steinpreis RE, Sherman JE, Baker TB (1990) Aversion instead of preference learning indicated by nicotine place conditioning in rats. Psychopharmacology 101:533-538.

Koob GF (1992) Drugs of abuse: anatomy, pharmacology and function of reward pathways. Trends Pharmacol Sci 13:177-184.

Koob GF (2000) Animal models of craving for ethanol. Addiction 95 [Suppl 2]:S73-S81.

Koob GF, Le Moal M (1997) Drug abuse: hedonic homeostatic dysregulation. Science 278:52-58.

Lichtman AH, Martin BR (1996) Delta 9-tetrahydrocannabinol impairs spatial memory through a cannabinoid receptor mechanism. Psychopharmacology 126:125-131.

Mallet PE, Beninger RJ (1998) The cannabinoid CB1 receptor antagonist SR141716A attenuates the memory impairment produced by $\Delta^{9}$ tetrahydrocannabinol or anandamide. Psychopharmacology 140:11-19.

McGregor IS, Issakidis CN, Prior G (1996) Aversive effects of the synthetic cannabinoid CP 55,940 in rats. Pharmacol Biochem Behav 53:657-664.

Naassila M, Pierrefiche O, Ledent C, Daoust M (2004) Decreased alcohol self-administration and increased alcohol sensitivity and withdrawal in CB1 receptor knockout mice. Neuropharmacology 46:243-253.

Oliva JM, Ortiz S, Palomo T, Manzanares J (2003) Behavioural and gene transcription alterations induced by spontaneous cannabinoid withdrawal in mice. J Neurochem 85:94-104.

Pertwee RG (1974) Tolerance to the effect of delta1-tetrahydrocannabinol on corticosterone levels in mouse plasma produced by repeated administration of cannabis extract or delta1-tetrahydrocannabinol. Br J Pharmacol 51:391-397.

Rasmussen DD, Boldt BM, Wilkinson CW, Mitton DR (2002) Chronic daily ethanol and withdrawal: 3 . Forebrain pro-opiomelanocortin gene expression and implications for dependence, relapse, and deprivation effect. Alcohol Clin Exp Res 26:535-546.

Rimondini R, Arlinde C, Sommer W, Heilig M (2002) Long-lasting increase in voluntary ethanol consumption and transcriptional regulation in the rat brain after intermittent exposure to alcohol. FASEB J 16:27-35.

Roberts AJ, Heyser CJ, Koob GF (1999) Operant self-administration of sweetened versus unsweetened ethanol: effects on blood alcohol levels. Alcohol Clin Exp Res 23:1151-1157.

Roberts AJ, Heyser CJ, Cole M, Griffin P, Koob GF (2000) Excessive ethanol drinking following a history of dependence: animal model of allostasis. Neuropsychopharmacology 22:581-594.

Rodd-Henricks ZA, McKinzie DL, Murphy JM, McBride WJ, Lumeng L, Li TK (2000) The expression of an alcohol deprivation effect in the highalcohol-drinking replicate rat lines is dependent on repeated deprivations. Alcohol Clin Exp Res 24:747-753.

Rodríguez ME, Anglin MD (1988) The epidemiology of alcohol consumption in Spain. Int J Soc Psychiatry 34:102-111.

Rodríguez de Fonseca F, Gorriti MA, Fernandez-Ruiz JJ, Palomo T, Ramos JA (1994) Downregulation of rat brain cannabinoid binding sites after chronic delta 9-tetrahydrocannabinol treatment. Pharmacol Biochem Behav 47:33-40.

Rodríguez de Fonseca F, Roberts AJ, Bilbao A, Koob GF, Navarro M (1999) Cannabinoid receptor antagonist SR141716A decreases operant ethanol self administration in rats exposed to ethanol-vapor chambers. Zhongguo Yao Li Xue Bao 20:1109-1114.

Rubino T, Massi P, Patrini G, Venier I, Giagnoni G, Parolaro D (1994) Chronic CP-55,940 alters cannabinoid receptor mRNA in the rat brain: an in situ hybridization study. NeuroReport 5:2493-2496.

Rubio P, Rodriguez de Fonseca F, Martin-Calderon JL, Del Arco I, Bartolome S, Villanua MA, Navarro M (1998) Maternal exposure to low doses of delta9-tetrahydrocannabinol facilitates morphine-induced place conditioning in adult male offspring. Pharmacol Biochem Behav 61:229-238.

Samson HH, Sharpe AL, Denning C (1999) Initiation of ethanol selfadministration using sucrose substitution in a sipper-tube procedure. Psychopharmacology 147:274-279.

Samson HH, Chappell A, Czachowski C, Sharpe A (2001) Measuring ethanol-seeking behavior: the effect of using repeated extinction trials. Alcohol 24:205-209.

Sañudo-Peña MC, Tsou K, Delay ER, Hohman AG, Force M, Walker JM (1997) Endogenous cannabinoids as an aversive or counter-rewarding system in the rat. Neurosci Lett 223:125-128.

Serra S, Carai MA, Brunetti G, Gómez R, Melis S, Vacca G, Colombo G, Gessa GL (2001) The cannabinoid receptor antagonist SR 141716 prevents acquisition of drinking behavior in alcohol-preferring rats. Eur J Pharmacol 430:369-371.

Serra S, Brunetti G, Pani M, Vacca G, Carai MA, Gessa GL, Colombo G (2002) Blockade by the cannabinoid $\mathrm{CB}(1)$ receptor antagonist, SR 141716, of alcohol deprivation effect in alcohol-preferring rats. Eur J Pharmacol 443:95-97.

Sinclair JD, Senter RJ (1967) Increased preference for ethanol in rats following alcohol deprivation. Psychon Sci 8:11-12.

Spanagel R, Hölter SM, Allingham K, Landgraf R, Zieglgänsberger W (1996) Acamprosate and alcohol. I. Effects on alcohol intake following alcohol deprivation in the rat. Eur J Pharmacol 305:39-44.

Thielen RJ, Engleman EA, Rodd ZA, Murphy JM, Lumeng L, Li TK, McBride WJ (2004) Ethanol drinking and deprivation alter dopaminergic and serotonergic function in the nucleus accumbens of alcohol-preferring rats. J Pharmacol Exp Ther 309:216-225.

Vengeliene V, Siegmund S, Singer MV, Sinclair JD, Li TK, Spanagel R (2003) A comparative study on alcohol-preferring rat lines: effects of deprivation and stress phases on voluntary alcohol intake. Alcohol Clin Exp Res 27: $1048-1054$. 